\title{
LECT2 association with macrophage-mediated killing of Helicobacter pylori by activating NF- $\kappa B$ and nitric oxide production
}

\author{
H.X. Shen ${ }^{1 *}$, L. Li ${ }^{2 *}$, Q. Chen ${ }^{1}$, Y.Q. He ${ }^{1}$, C.H. Yu ${ }^{2}$, C.Q. Chu ${ }^{1}$, X.J. Lu ${ }^{1}$ \\ and J. Chen ${ }^{1}$ \\ ${ }^{1}$ Laboratory of Biochemistry and Molecular Biology, Ningbo University, \\ Ningbo, China \\ ${ }^{2}$ Department of Gastroenterology, The First Affiliated Hospital, \\ College of Medicine, Zhejiang University, Hangzhou, China \\ *These authors contributed equally to this study. \\ Corresponding authors: X.J. Lu / J. Chen \\ E-mail:1xj711043@163.com / jchen1975@163.com
}

Genet. Mol. Res. 15 (4): gmr15048889

Received June 16, 2016

Accepted July 25, 2016

Published October 24, 2016

DOI http://dx.doi.org/10.4238/gmr15048889

Copyright $(2016$ The Authors. This is an open-access article distributed under the terms of the Creative Commons Attribution ShareAlike (CC BY-SA) 4.0 License.

\begin{abstract}
Helicobacter pylori employs unique methods to colonize the stomach, which induces chronic inflammation. It is also able to avoid eradication by macrophages and other immune cells. Leukocyte cell-derived chemotaxin 2 (LECT2), a multi-functional cytokine involved in many pathological conditions, has recently been shown to activate macrophages via the $\mathrm{CD} 209 \mathrm{a}$ receptor. Therefore, we aimed to investigate the effects of LECT2 on $\mathrm{H}$. pylori-infected macrophages. Macrophages were treated with recombinant LECT2, and both their ability to kill $H$. pylori and produce nitric oxide were analyzed. Western blot was performed to determine nuclear translocation and protein phosphorylation of $\mathrm{p} 65$, a subunit of nuclear factor (NF)-кB.
\end{abstract}

Genetics and Molecular Research 15 (4): gmr15048889 
Transfection experiments were performed to analyze the signaling pathway of LECT2 in macrophages. We found that treatment with LECT2 enhanced $H$. pylori killing and nitric oxide production in macrophages. In addition, DNA-binding activity and nuclear translocation of p65 were up-regulated by LECT2 treatment. Furthermore, we found that NF$\kappa \mathrm{B}$ activation by LECT2 was mediated by Raf- 1 in macrophages, and Raf-1 phosphorylation was specifically altered in response to LECT2. Moreover, LECT2 induced Ser28 phosphorylation in the intracellular domain of CD209a. CD209a Ser28 phosphorylation was required for LECT2-induced Raf-1 and NF- $\kappa B$ activation in RAW264.7 macrophages. Our study showed that the effects of LECT2 on H. pylori killing and nitric oxide production were dependent on CD209a phosphorylation, Raf-1, and NF- $\kappa \mathrm{B}$ activation. Together, these results demonstrate for the first time that exposure to LECT2 can modulate specific intracellular mechanisms downstream of CD209a to enhance H. pylori killing and nitric oxide production in macrophages.

Key words: LECT2; CD209a; Macrophages; Helicobacter pylori; Bacterial killing; NF- $\mathrm{\kappa B}$

\section{INTRODUCTION}

Helicobacter pylori, a Gram-negative spiral bacterium, is the most common pathogen in the world, and the causative agent of chronic gastritis, peptic ulcer disease, and gastric mucosa-associated lymphoid tissue lymphoma (Cid et al., 2013; Hong et al., 2016). Furthermore, long-term H. pylori infection may lead to the development of gastric cancer, the second largest cause of cancer-related deaths worldwide (Polk and Peek, 2010). The adherence of $H$. pylori to the gastric epithelium results in pathogenicity. However, the inflammatory response generated during this process is often not enough to resolve the infection, leading to chronic H. pylori infection that can last for decades (Kumar et al., 2015; Hu et al., 2016). Beside its interaction with gastric epithelial cells, H. pylori also affects the recruitment and activation of other immune cells, including $\mathrm{T}$ cells and myeloid cells (Chen et al., 2015; Hardbower et al., 2016). Macrophages are important players in the host's defense against H. pylori infections (Yamauchi et al., 2008; Ansari et al., 2014). H. pylori infections trigger nuclear factor (NF)- $\mathrm{BB}$-mediated pro-inflammatory signaling pathway in epithelial cells and macrophages (Ahmed et al., 2014; Kim et al., 2016). Inflammatory stimuli up-regulate inducible nitric oxide synthase (iNOS) expression in macrophages to produce nitric oxide (NO), which can kill H. pylori (Chaturvedi et al., 2007). Hence, it is possible that increased NO production by macrophages will enhance their ability to kill $H$. pylori.

Leukocyte cell-derived chemotaxin 2 (LECT2) is a multi-functional protein produced in the liver, and is secreted into the blood in humans and other vertebrates (Yamagoe et al., 1998). It has been reported that LECT2 is involved in many pathological conditions, including renal amyloidosis (Benson et al., 2008), hepatocarcinogenesis (Uchida et al., 1999), rheumatoid arthritis (Kameoka et al., 2000), severe liver injury (Saito et al., 2004), and staphylococcal enterotoxin A-induced toxicity (Dang et al., 2010). Recently, we showed that LECT2 improves survival of septic mice by activation of macrophages via the CD209a

Genetics and Molecular Research 15 (4): gmr15048889 
receptor (Lu et al., 2013). In addition, microarray analysis showed that LECT2 treatment upregulates several NF-אB family genes (Lu et al., 2013).

There are several homologs of dendritic cell-specific intercellular adhesion molecule-3grabbing non-integrin (DC-SIGN) in mice, including SIGNR1-5 (CD209b, CD209c, CD209d, CD209e, and CD209a), which belong to the C-type lectin receptor (CLR) family (Park et al., 2001). NF-кB plays an important role in downstream signaling of some CLRs. For example, Dectin-1 can activate NF-KB through the Raf-1 and Syk kinase-dependent signaling pathways (Sancho and Reis e Sousa, 2012). DC-SIGN has also been found to modulate NF- $\kappa B$ activity

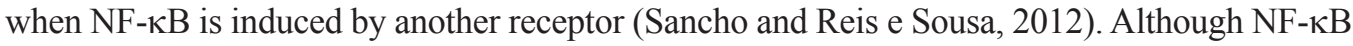
activation is mediated through various signaling molecules, including protein kinase (PK) $\mathrm{C} \delta$, Akt, and IкB kinase (Oeckinghaus et al., 2011), there is little information regarding the signaling pathways that regulate NF- $\mathrm{kB}$ activation following CLR-mediated stimulation in macrophages.

In this study, we sought to determine the effects of LECT2 on macrophage responses during $H$. pylori infections. Our data showed that LECT2-treated macrophages possess enhanced ability to kill $H$. pylori and produce NO. Furthermore, we aimed to elucidate the signaling pathways underlying CD209a activation in LECT2-treated macrophages to determine their significance during infections. We found that the cellular effects induced by LECT2 were most likely mediated by Raf-1, which contributed to NF- $\mathrm{kB}$ activation triggered by the LECT2/CD209a interaction.

\section{MATERIAL AND METHODS}

\section{Ethics statement}

All experiments involving animals were conducted according to relevant national and international guidelines. All animal care and experimental procedures were approved by the Committee on Animal Care and Use and Committee on the Ethics of Animal Experiments of Ningbo University (Zhejiang, China).

\section{Mice and peritoneal macrophages}

Male B6 mice (6-8 weeks old) were purchased from Zhejiang Province Experimental Animal Center (Zhejiang, China). CD209a knockout mice on B6 background (6-8 weeks old) were purchased from the Mutant Mouse Resource Regional Center. The total number of wild type mice used for cell culture was 196, and the number of CD209a knockout mice used was 8 . For peritoneal macrophage isolation, mice were injected intraperitoneally with $2 \mathrm{~mL}$ thioglycollate broth to elicit peritoneal macrophages. Four days later, cells were collected by lavaging the peritoneal cavity with ice-cold RPMI-1640 medium. The isolated cells were then washed and resuspended in RPMI-1640 supplemented with $10 \%(\mathrm{v} / \mathrm{v})$ heat-inactivated fetal bovine serum (FBS; Invitrogen, Shanghai, China), $2 \mathrm{mM}$ glutamine, $100 \mathrm{U} / \mathrm{mL}$ penicillin, and $100 \mu \mathrm{g} / \mathrm{mL}$ streptomycin. Cells were seeded (in triplicates) at a density of $1 \times 10^{6} / \mathrm{mL}$ on $24-$ or 96-well plates (Corning, Acton, MA, USA), and allowed to adhere for $2 \mathrm{~h}$ at $37^{\circ} \mathrm{C}$ under $5 \%$ $\mathrm{CO}_{2}$. Cells were then washed twice to remove non-adherent cells, supplied with fresh medium as described above, and allowed to rest for 18-24 h. Recombinant mouse LECT2 proteins were generated from Chinese hamster ovary cells, as previously described (Lu et al., 2013). In all experiments, $5 \mu \mathrm{g} / \mathrm{mL}$ LECT2 was used for treatment.

Genetics and Molecular Research 15 (4): gmr15048889 


\section{Macrophage-mediated killing of $\boldsymbol{H}$. pylori}

Following a 30-min LECT2 treatment, macrophages were infected with $H$. pylori at a multiplicity of infection of 20 for either $30 \mathrm{~min}$ or $8 \mathrm{~h}$, before being lysed with $0.1 \%(\mathrm{w} / \mathrm{v})$ saponin (in PBS) for $15 \mathrm{~min}$ at $37^{\circ} \mathrm{C}$. Serial dilutions of the macrophage lysates were plated, and viable $H$. pylori cells were enumerated. Bacterial killing was determined by the number of colony-forming units per well.

\section{Measurement of NO concentration}

The concentration of the oxidized $\mathrm{NO}$ metabolite, nitrite $\left(\mathrm{NO}_{2}^{-}\right)$, was assessed via the Griess reaction (Granger et al., 1996). For these experiments, macrophages were plated at a density of $1 \times 10^{6}$ cells $/ \mathrm{mL}$, and the results were expressed as $\mu \mathrm{M} \mathrm{NO}_{2}^{-}$.

\section{RAW264.7 macrophage culture and transfection}

The mouse macrophage-like cell line RAW264.7 was purchased from the American Tissue Culture Collection (Manassas, VA, USA), and was cultured in DMEM (Invitrogen) supplemented with $10 \%(\mathrm{v} / \mathrm{v}) \mathrm{FBS}$ at $37^{\circ} \mathrm{C}$ and $5 \% \mathrm{CO}_{2}$. The NetPhos version 2.0 prediction server (http://www.cbs.dtu.dk/services/NetPhos/) (Blom et al., 1999) was used to identify phosphorylation sites; residues with scores $>0.95$ were selected. In the CD209a intracellular domain, Ser28 was the potential phosphorylation site chosen for further investigation. Wildtype and mutant CD209a (Ser28 to Ala mutant, S28A) were cloned into pFB-Neo vectors, which were transfected into HEK293T-based Phoenix ${ }^{\mathrm{TM}}$ ecotropic packaging cells, using FuGENE ${ }^{\circledR}$ 6 (Roche, Shanghai, China). Retroviral supernatants were collected after $48 \mathrm{~h}$ to transduce RAW264.7 macrophages. Cells were selected and maintained in $0.6 \mathrm{mg} / \mathrm{mL}$ geneticin (SigmaAldrich, St Louis, MO, USA) and $0.4 \mathrm{mg} / \mathrm{mL}$ Zeocin $^{\mathrm{TM}}$ (Invitrogen). RAW264.7 macrophages were cultured on 24 -well plates at $2 \times 10^{6}$ cells per well.

\section{Inhibitors and RNAi treatments}

The following inhibitors were used: $4 \mu \mathrm{M}$ U0126 (MEK1/2 inhibitor), $5 \mu \mathrm{M} \mathrm{LY} 294002$ (phosphatidylinositol 3-kinase inhibitor), $2.5 \mu \mathrm{M}$ API-2 (PKB inhibitor), $1 \mu \mathrm{M}$ H89 (PKA inhibitor), $18 \mu \mathrm{M}$ SN50 (NF-кB inhibitor) (all from Calbiochem, San Diego, CA, USA), 1 $\mu \mathrm{M}$ GW5074 (Raf-1 inhibitor), $40 \mu \mathrm{M}$ piceatannol (Syk inhibitor), and $1 \mu \mathrm{M}$ SB203580 [p38 mitogen-activated protein kinase (MAPK) inhibitor] (all from Sigma-Aldrich). Stealth RNAi duplexes against CD209a (5'-AUCUACGCCAGCCUUCAACUGGGUC-3') were purchased from Invitrogen; The method for CD209a protein knock-down following CD209a siRNA transfection was previously demonstrated (Lu et al., 2013).

\section{Analysis of DNA-binding activity}

DNA-binding activity was determined using the TransAM ${ }^{\circledR}$ enzyme-linked immunosorbent assay (ELISA) kit (Active Motif, Carlsbad, CA, USA), following the manufacturer protocol. Nuclear extracts were prepared according to the user manual (Active Motif), and assayed for NF- $\mathrm{kB}$ DNA-binding activity following the manufacturer protocol.

Genetics and Molecular Research 15 (4): gmr15048889 
Absorbance was read at $450 \mathrm{~nm}$ with a reference wavelength of $655 \mathrm{~nm}$.

\section{Western blot analysis}

Cell monolayers were washed twice with PBS and scraped in lysis buffer (20 $\mathrm{mM}$ 4-(2-hydroxyethyl)-1-piperazineethanesulfonic acid, $1.5 \mathrm{mM} \mathrm{MgCl}_{2}, 0.2 \mathrm{mM}$ EDTA, $100 \mathrm{mM} \mathrm{NaCl}, 0.2 \mathrm{mM}$ dithiothreitol, $0.5 \mathrm{mM}$ sodium orthovanadate, $0.4 \mathrm{mM}$ phenylmethanesulfonylfluoride, $\mathrm{pH}$ 7.4) containing phosphatase inhibitors (phosphatase inhibitor cocktail, Sigma-Aldrich). To isolate nuclear and cytoplasmic proteins, cells were harvested in PBS and centrifuged. The pellets were resuspended sequentially in low salt, sucrose, and high salt solutions to obtain cytosolic and highly purified nuclear extracts, as previously described (Forbus et al., 2006). Protein concentration of the supernatant was measured by the Bradford method. Proteins were resolved by SDS-PAGE, followed by electrophoretic transfer from gels to membranes. After membranes were blocked, they were incubated with the appropriate primary and horseradish peroxidase-linked secondary antibodies. Proteins of interest were detected by enhanced chemiluminescence. The following primary antibodies were used: anti-CD209a and anti-phospho-CD209aSer28 (GL Biochem, Shanghai, China); anti-p65, anti-tubulin, and anti-lamin (Santa Cruz Biotechnology, Dallas, TX, USA); antiphospho-Raf-1Ser338 and anti-phospho-Raf-1Ser259 (Cell Signaling Technology, Beverly, MA, USA); and anti-Raf-1 (Millipore, Billerica, MA, USA).

\section{Real-time quantitative PCR}

Total RNA was extracted and purified from macrophages. After deoxyribonuclease I treatment, total RNA was reverse transcribed using Moloney murine leukemia virus reverse transcriptase (RNase H-) (TaKaRa Bio, Dalian, China). Quantitative real-time PCR (qPCR) was carried out on a StepOne ${ }^{\mathrm{TM}}$ instrument (Applied Biosystems, Foster City, CA, USA). Detection of mRNAs were carried out with the $\mathrm{SYBR}^{\circledR}$ premix Ex Taq ${ }^{\mathrm{TM}}$ (TaKaRa) mastermix. Primers specific for granulocyte colony-stimulating factor, (G-CSF) (+): 5'-GGGAAGGAGATGGGTAAAT-3' and G-CSF (-): 5'-GGAAGGGAGACCAGATGC-3', were used to amplify a 147-base pair (bp) fragment of the $G$-CSF gene transcript. As an internal PCR control, primers specific for 18S rRNA (+): 5'-TTTGTTGGTTTTCGGAACTGA-3' and 18S rRNA (-): 5'-CGTTTATGGTCGGAACTACGA-3' were used to amplify a 198-bp fragment of this housekeeping gene.

\section{Cytokine assay}

Cell culture media were centrifuged at 14,000 rpm for $5 \mathrm{~min}$, and the supernatant fractions were stored in aliquots at $-80^{\circ} \mathrm{C}$ until use. G-CSF ELISAs were conducted following manufacturer protocol (R\&D Systems, Minneapolis, MN, USA).

\section{Statistical analysis}

Data are reported as means \pm SEM. Data were analyzed by one-way ANOVA, followed by post hoc tests to calculate the least significant difference between individual groups. In all cases, $\mathrm{P}<0.05$ was considered statistically significant.

Genetics and Molecular Research 15 (4): gmr15048889 


\section{RESULTS}

\section{Effect of LECT2 on H. pylori killing by macrophages}

Following a 30-min $H$. pylori infection, the number of viable cells were comparable between LECT2-treated and control macrophage cultures (Figure 1A). The number of viable $H$. pylori cells was significantly reduced in both saline- and LECT2-treated macrophage cultures after the 8-h infection period as compared with that measured after the 30-min infection (Figure 1A). In addition, the number of viable H. pylori in LECT2-treated macrophage cultures after the 8-h infection was significantly lower than that in the saline-treated macrophage cultures (Figure 1A). Several previous studies have reported $H$. pylori killing as a result of NO production by macrophages (Bussière et al., 2005; Chaturvedi et al., 2007). Our results showed that NO production in response to $H$. pylori was similar between saline-and LECT2treated macrophage cultures after a 30-min infection (Figure 1B). However, NO production by both saline- and LECT2-treated macrophages was significantly up-regulated after a 8-h infection period (Figure 1B). Furthermore, LECT2 stimulation up-regulated NO production in macrophages during the 8-h H. pylori infection (Figure 1B).

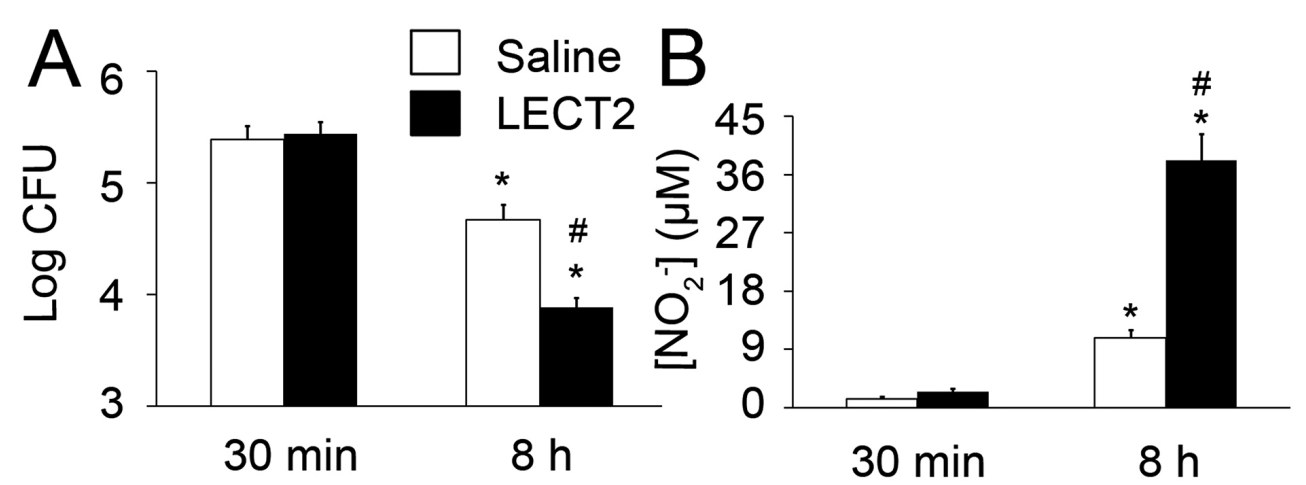

Figure 1. Effects of LECT2 treatment on killing of Helicobacter pylori and NO production by macrophages. Following saline or LECT2 treatment, murine peritoneal macrophages were infected with $H$. pylori, and incubated for either $30 \mathrm{~min}$ or $8 \mathrm{~h}$. A. LECT2 stimulated macrophage-mediated killing of $H$. pylori. The number of viable $H$. pylori recovered from infected macrophages was represented as colony forming units per $\mathrm{mL}(\mathrm{CFU} /$ $\mathrm{mL}$ ). B. Treatment with LECT2 stimulated NO production by $H$. pylori-infected macrophages. $\mathrm{N}=3$ in each group. ${ }^{*} \mathrm{P}<0.05$ vs 30 min-group, ${ }^{\#} \mathrm{P}<0.05$ vs saline group.

\section{LECT2 treatment leads to NF- $\mathrm{BB}$ activation in macrophages}

NF- $\kappa B$ activation was analyzed following LECT2 treatment via DNA-binding ELISA. The p65 DNA-binding activity did not change following $H$. pylori infection (Figure 2A). However, the DNA-binding activity of p65 showed a 1.89-fold increase in LECT2-treated peritoneal macrophages as compared with that in saline-treated control cells (Figure 2A). We next sought to explore the effect of LECT2 on the intracellular distribution of p65. Stimulation of macrophages with LECT2 resulted in decreased cytoplasmic p65 expression as compared with that in saline-treated cells (Figure 2B). In contrast, nuclear translocation of p65 was significantly increased by LECT2 treatment (Figure 2C). Taken together, these results clearly

Genetics and Molecular Research 15 (4): gmr15048889 
demonstrated that LECT2 stimulates p65 nuclear localization, and increases its DNA-binding activity in both $H$. pylori-infected and uninfected macrophages.
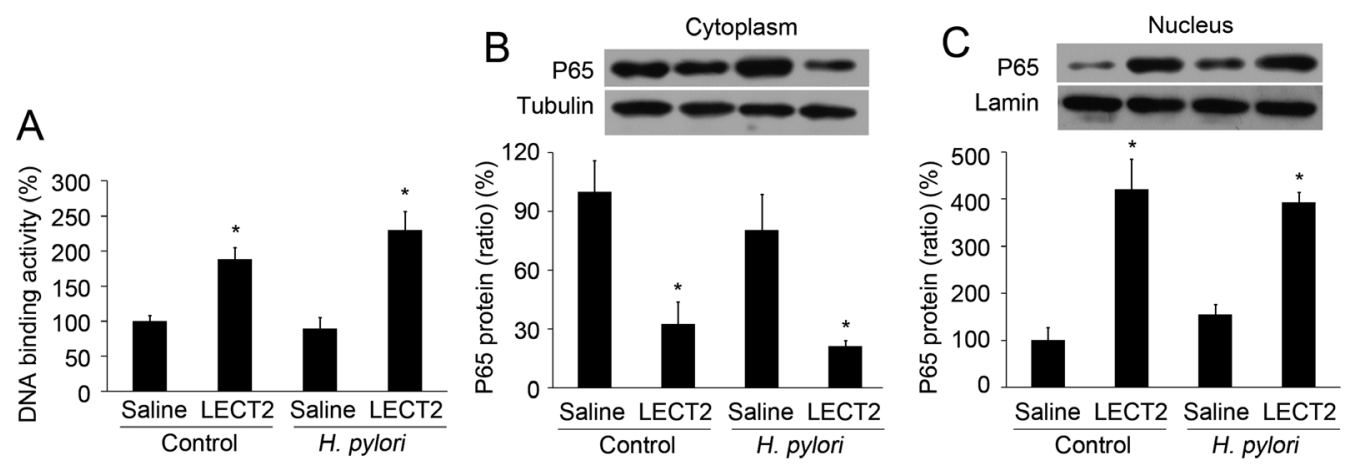

Figure 2. LECT2 treatment leads to NF- $\mathrm{KB}$ activation during Helicobacter pylori infection in macrophages. A. Bar charts show the relative DNA-binding activity of $\mathrm{p} 65$ in the nucleus. Murine peritoneal macrophages were treated with either LECT2 or saline for $3.5 \mathrm{~h}$. B. Peritoneal macrophages were treated with either LECT2 or saline for $3.5 \mathrm{~h}$, and cytoplasmic p65 content was analyzed by western blot. C. LECT2 induced nuclear translocation of p65. Tubulin and lamin were quantified as loading controls in the cytoplasm and nucleus, respectively. $\mathrm{N}=3$ in each group. ${ }^{*} \mathrm{P}<0.05$.

\section{Raf-1 is essential for LECT2/CD209a signaling}

We further investigated the molecular mechanisms underlying the response induced when LECT2 binds to CD209a in macrophages. A series of specific inhibitors directed against a broad range of potentially important signaling proteins were used. As G-CSF was dramatically up-regulated upon LECT2 treatment (Lu et al., 2013), it was used as an indicator of LECT2/ CD209a signaling. Treatment with the Raf-1 inhibitor GW5074 completely abrogated G-CSF production in LECT2-treated macrophages (Figure 3A), whereas none of the other inhibitors had any effect on LECT2-induced G-CSF production (Figure 3A).

Raf-1 activation is tightly regulated via phosphorylation and de-phosphorylation by specific serine, threonine, and tyrosine residues within its structure (Dhillon et al., 2007). Of these residues, Ser259 is an inhibitory phosphorylation site, whereas Ser338 phosphorylation is required for optimal Raf-1 kinase activity. Here, we found that LECT2 up-regulated Raf-1 Ser338 phosphorylation and down-regulated Ser259 phosphorylation in normal macrophages (Figure 3B). Moreover, we demonstrated that CD209a knockdown inhibited LECT2-induced phosphorylation of both Ser338 and Ser259 residues on Raf-1 (Figure 3B).

Several studies have suggested that Raf-1 plays a role in modulating NF- $\kappa B$ transactivation (Gringhuis et al., 2009). Macrophages stimulated with the Raf-1 antagonist GW5074 did not show any changes in the DNA-binding activity of p65. However, LECT2 up-regulated the DNA-binding activity of p65 (Figure 3C). Strikingly, cells treated with a combination of GW5074 and LECT2 did not result in any detectable change in p65 DNAbinding activity (Figure 3C), indicating that LECT2-mediated activation of p65 is mediated by Raf- 1 . 

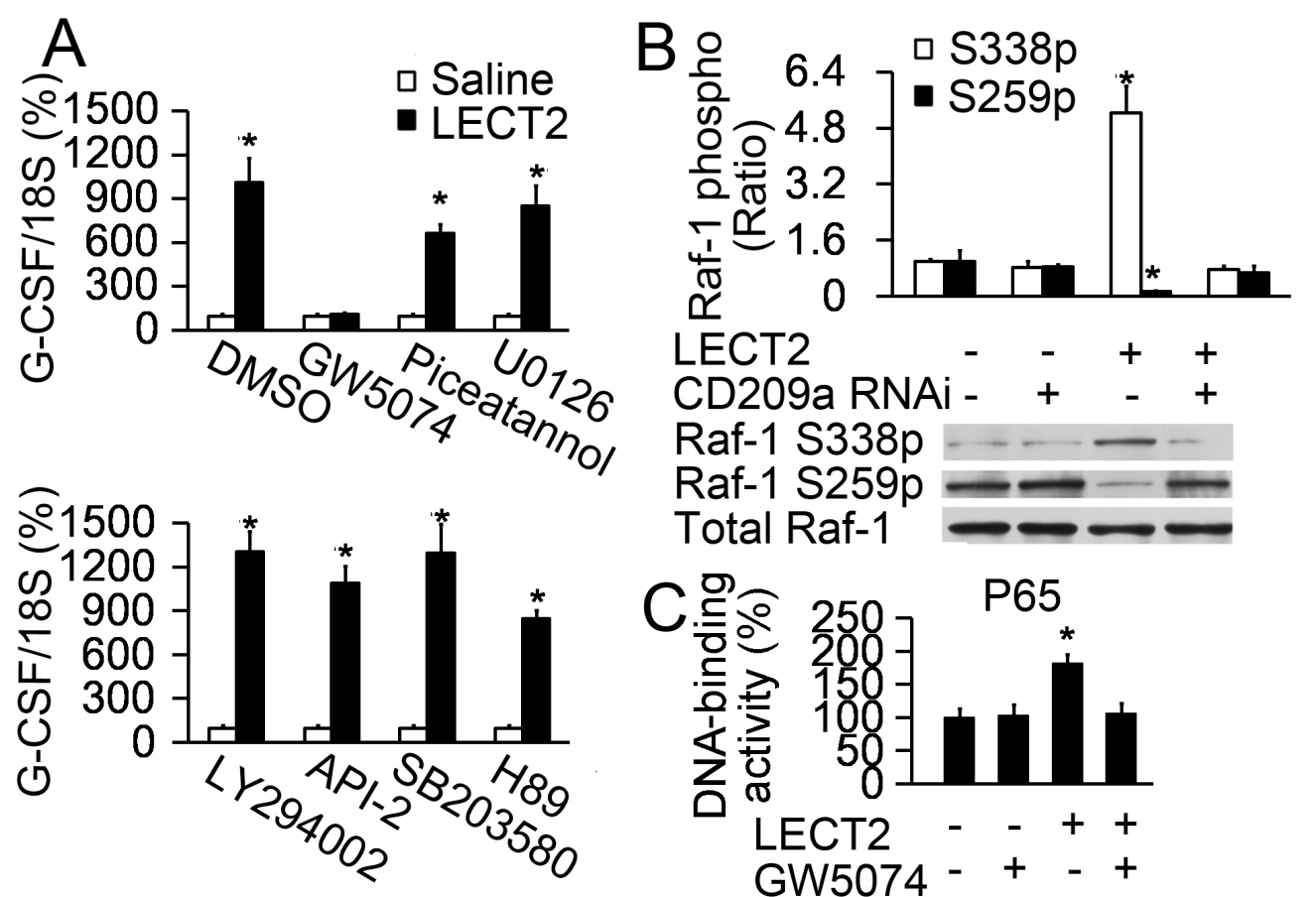

Figure 3. Raf-1 is part of the LECT2/CD209a signaling pathway in macrophages. A. Relative $G$-CSF mRNA expression in murine peritoneal macrophages. Cells were treated with LECT2 for $3.5 \mathrm{~h}$ in the presence of the inhibitors GW5074, piceatannol, SB203580, U0126, LY294002, API-2, or H89. 0.1\% (v/v) DMSO was used as control. Relative expression of G-CSF mRNA was determined by qPCR ( $N=4$ in each group). B. Interaction between LECT2 and CD209a induced Raf-1 activation in peritoneal macrophages. Blots are representative of three independent experiments. C. LECT2/CD209a signaling induced NF- $\mathrm{kB}$ nuclear translocation through Raf-1 activation in peritoneal macrophages. Nuclear extracts were assayed for DNA-binding activity of $\mathrm{p} 65 . \mathrm{N}=4$ in each group. $* \mathrm{P}<0.05$.

\section{Phosphorylation of CD209a at Ser28 is necessary for LECT2 signaling}

CD209a does not contain a YXXI/L domain, which is required for signaling through certain CLRs such as CLEC-2 and Dectin-1 (Hughes et al., 2013). To investigate the role of the CD209a intracellular domain in LECT2/CD209a signaling, potential phosphorylation sites were identified using the NetPhos version 2.0 phosphorylation prediction program. Ser 28 was predicted to be the only phosphorylation site in the CD209a cytoplasmic tail (NetPhos score = 0.997), and was therefore chosen for further study.

We found that following LECT2 treatment, Ser28 was phosphorylated on CD209a in macrophages from wild-type mice, but not in those from knockout mice (Figure 4A). To determine whether CD209a Ser28 phosphorylation was important in regulating Raf-1 and NF$\kappa \mathrm{B}$ activation, Ser28 was mutated to Ala (S28A) to render the residues non-phosphorylatable in CD209a-transfected RAW264.7 cells (Figure 4B). The S28A CD209a-transfected RAW264.7 macrophages (RAW264.7-CD209a-S28A) did not show increased Raf-1 activation with LECT2 treatment as compared with the control cells (RAW264.7-CD209a-WT) (Figure 4C).

Genetics and Molecular Research 15 (4): gmr15048889 
LECT2 treatment induced greater NF- $\kappa B$ DNA-binding activity and G-CSF expression in RAW264.7-CD209a-WT as compared with that in saline-treated cells (Figure 4D and E). However, NF- $\kappa$ B DNA-binding activity or G-CSF expression in RAW264.7 CD209a-S28A was comparable to that in saline-treated cells following LECT2 treatment (Figure 4D and E).

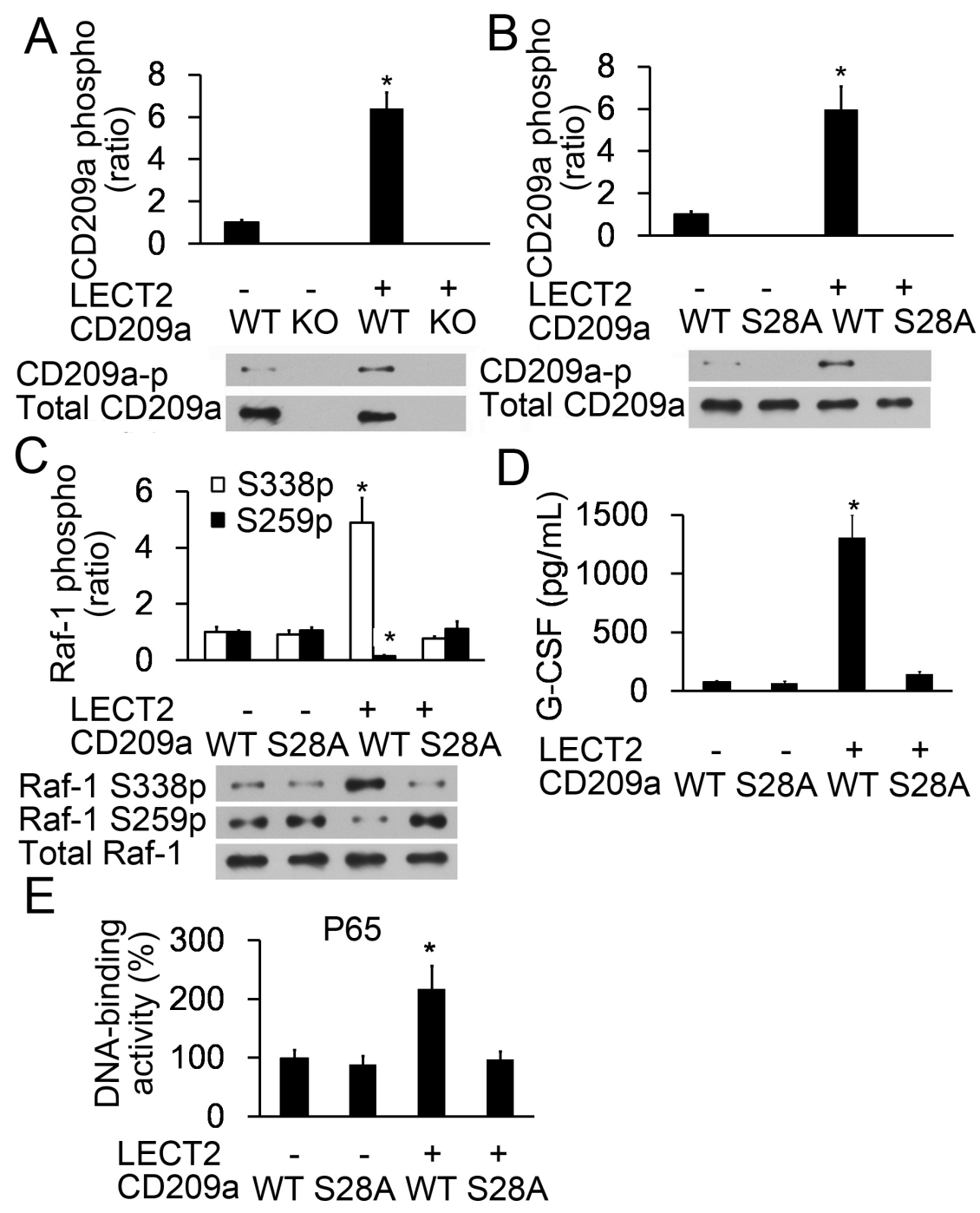

Figure 4. CD209a phosphorylation mediates LECT2-induced activation of NF-kB signaling pathway. A. Proteins were extracted from macrophages and used for western blot analysis. B. CD209a phosphorylation was measured after LECT2 treatment. RAW264.7 cells were transfected with either wild-type or mutated S28A CD209a. C. Raf-1 phosphorylation was examined after LECT2 treatment in RAW264.7-CD209a-WT or RAW264.7-CD209a-S28A cells. Blots are representative of three independent experiments. D. G-CSF expression was measured by ELISA after LECT2 treatment in RAW264.7-CD209a-WT or RAW264.7-CD209a-S28A cells. E. DNA-binding activity of p65 was measured after LECT2 treatment in RAW264.7-CD209a-WT or RAW264.7-CD209a-S28A cells. N = 4 each group. ${ }^{*} \mathrm{P}<0.05$.

Genetics and Molecular Research 15 (4): gmr15048889 


\section{LECT2/CD209a interaction promotes increased $H$. pylori killing via the Raf-1-NF-KB pathway}

We next measured $H$. pylori killing and NO production in LECT2-treated CD209atransfected RAW264.7 cells to elucidate the signaling pathways underlying the LECT2/ CD209a interaction. As shown in Figure 5A, treatment with LECT2 for $8 \mathrm{~h}$ significantly increased H. pylori killing and NO production in RAW264.7-CD209a-WT as compared with that in saline-treated cells; however, the stimulatory effect of LECT2 treatment on $\mathrm{H}$. pylori killing by macrophages was abrogated in the presence of the NF- $\mathrm{kB}$ inhibitor SN50. Moreover, SN50 also prevented NO production by macrophages following LECT2 treatment (Figure 5A). In RAW264.7-CD209a-S28A, H. pylori killing and NO production were not altered after LECT2 treatment (Figure 5B). Furthermore, treatment of macrophages with GW5074 prevented LECT2 - induced $H$. pylori killing and NO production (Figure 5C).

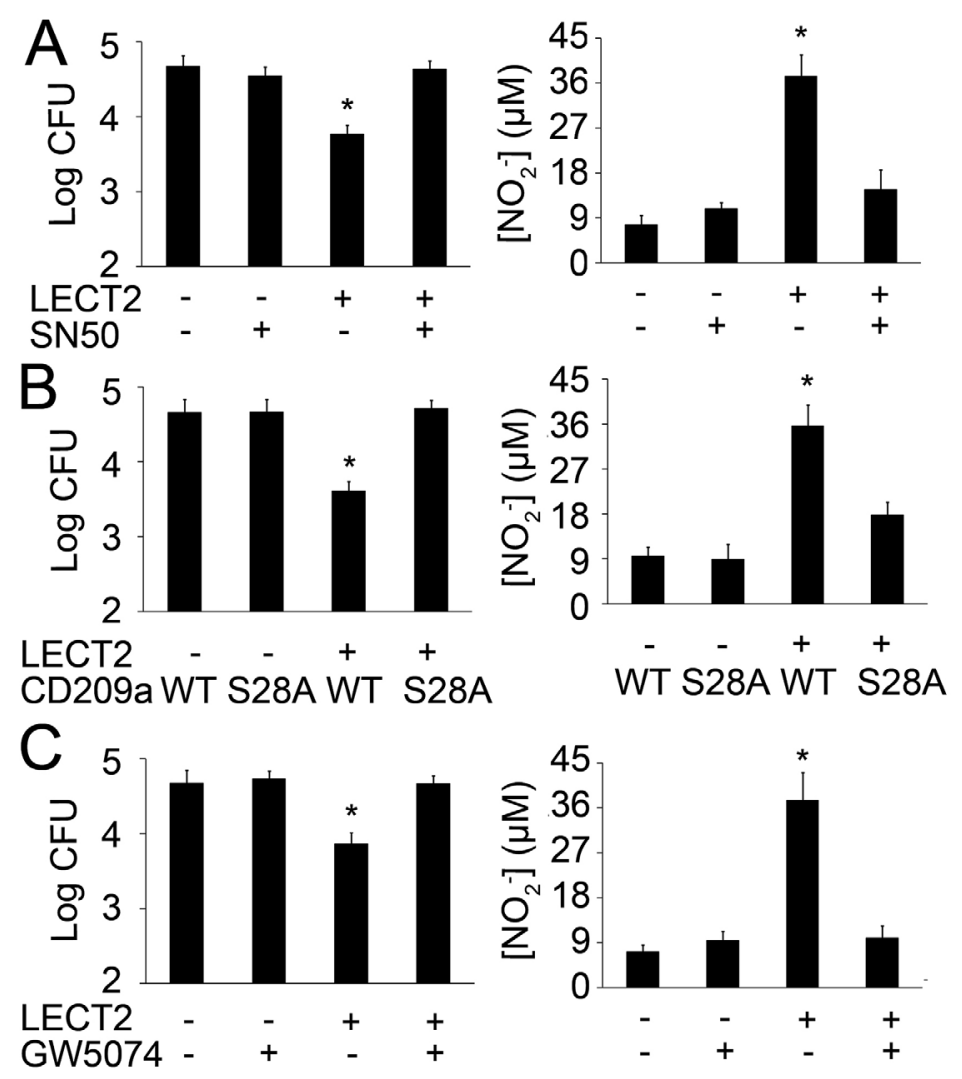

Figure 5. CD209a-NF- $\mathrm{B}$ signaling pathway mediates the effects of LECT2 on Helicobacter pylori killing and NO production in macrophages. H. pylori killing and NO production by the macrophages were measured following LECT2 treatment. A. Effects of the NF-kB inhibitor, SN50, on H. pylori killing and NO production by RAW264.7CD209a-WT. SN50 was treated $2 \mathrm{~h}$ before LECT2 induction. B. Effects of CD209a phosphorylation on H. pylori killing and NO production in RAW264.7-CD209a-WT or RAW264.7-CD209a-S28A. C. Effects of Raf-1 on $H$. pylori killing and NO production in RAW264.7-CD209a-WT. The Raf-1 inhibitor GW5074 was administered to RAW264.7 cells $2 \mathrm{~h}$ before LECT2 treatment. $\mathrm{N}=3$ in each group. $* \mathrm{P}<0.05$. 


\section{DISCUSSION}

LECT2, a multifunctional cytokine, was identified as a macrophage regulator ( $\mathrm{Lu}$ et al., 2013). Here, we demonstrated LECT2-mediated NO production by macrophages, which contributed to increased H. pylori killing. Furthermore, we showed that LECT2 induced Ser28 phosphorylation on CD209a, leading to Raf-1-mediated activation of NF- $\mathrm{KB}$ in macrophages. This is the first study to identify LECT2 as a cytokine that increases $H$. pylori killing and NO production via regulation of the CD209a-NF- $\mathrm{KB}$ signaling pathway in macrophages.

Macrophages, coordinators of the immune response, are the first line of defense against bacteria (Abdullah and Knolle, 2014). Exposure of macrophages to most pathogenic bacteria results in iNOS and NO production (Huang et al., 2002). For example, H. pylori infection leads to an increase in iNOS mRNA expression in macrophages. It also induces a modest increase in iNOS and NO expression, which assists pathogens to evade host defenses (Chaturvedi et al., 2012). We also found that $H$. pylori killing and NO production by macrophages were up-regulated following LECT2 treatment as compared with that in cells treated with saline, indicating that $\mathrm{NO}$ plays a crucial role in LECT2-induced $H$. pylori killing.

We further investigated the signaling pathway associated with increased NO production by macrophages after LECT2 treatment. NF- $\mathrm{KB}$ plays a key role in regulating macrophage immune responses to infections, and is the central integrator of pro-inflammatory signaling pathways (Hayden and Ghosh, 2011). However, H. pylori infection does not induce the translocation of active NF- $\mathrm{BB}$ into the nucleus ( $\mathrm{Lu}$ et al., 2012). We identified the NF$\kappa \mathrm{B}$ subunit $\mathrm{p} 65$ as the main transcription factor involved in LECT2-mediated macrophage activation. In macrophages, the NF- $\mathrm{BB}$ DNA-binding domain is present in the promoters of LECT2-induced genes, such as G-CSF, IFN- $\gamma$, CXCL10, IL-10, and C3 (Lu et al., 2013). Thus, we hypothesized that NF- $\mathrm{kB}$ activation is a key event in the LECT2 signaling pathway, and is responsible for LECT2-mediated gene expression changes. In our data, treatment with SN50, a NF-kB inhibitor, reduced LECT2-induced H. pylori killing and NO production in macrophages. Since NF- $\kappa B$ activation can stimulate iNOS, leading to enhanced NO production (Jones et al., 2007), our results may preliminarily indicate that NF- $\kappa B$ activation by LECT2 mediates NO production to enhance $H$. pylori killing by macrophages.

Our previous study had shown that LECT2 affects macrophages through CD209 (Lu et al., 2013). Here, we investigated intracellular signaling in macrophages due to LECT2 and CD209a interactions. A unique feature of the LECT2/CD209a signaling cascade is CD209a Ser28 phosphorylation, which is required for further downstream signaling and $\mathrm{H}$. pylori killing. CD209a is a mouse homolog of human DC-SIGN, which can recognize $H$. pylori (Castaño-Rodríguez et al., 2014). However, we found that CD209a does not recognize $H$. pylori in macrophages (data not shown). Hence, CD209a is not a pattern recognition receptor for $H$. pylori, but mediates the effect of LECT2, which leads to $H$. pylori killing. The cytoplasmic signaling downstream of CLRs has been shown in a study by Osorio and Reis e Sousa (2011). Although the human homolog of CD209a, DC-SIGN, has been found to activate NF- $\mathrm{BB}$ (Gringhuis et al., 2007), the existence and location of any phosphorylation site on the intracellular tail of DC-SIGN remain unknown. Other CLRs have phosphorylation sites that are involved in downstream signaling events, for example, phosphorylation of the CLEC-2 cytosolic tyrosine residue is sufficient for binding and activating Syk (Suzuki-Inoue et al., 2006). Based on these results, we infer that CLRs can influence cellular behaviors through a wide variety of intracellular signaling pathways via their intracellular tail domains. For

Genetics and Molecular Research 15 (4): gmr15048889 
many CLRs, Syk acts as a critical node for subsequent activation of the NF- $\mathrm{BB}$, MAPK, and nuclear factors in activated T cells. Moreover, Raf-1 can act via a Syk-independent pathway to regulate NF- $\kappa B$ activity (Gringhuis et al., 2009). Our results showed that LECT2 enhanced $\mathrm{NF}-\kappa \mathrm{B}$ activity in macrophages via binding to CD209a. It has been demonstrated previously that Raf-1 activity induced by DC-SIGN leads to modulation of Toll-like receptor signaling via NF- $\mathrm{KB}$ (Gringhuis et al., 2007). In addition, in a recent study, Raf-1 was shown to mediate the activation of the LECT2/CD209a signaling pathway, thus contributing to increased $H$. pylori killing and NO production by macrophages. Raf-1 plays an important role in regulating the proliferation, differentiation, survival, and motility of cells, as an effector of Ras in the signaling cascade. It activates MAPK following stimulation by antigens, cytokines, and growth factor receptors (Baccarini, 2005). However, the exact mechanism of how LECT2 induces Raf-1 activation via CD209 needs to be further investigated.

In summary, these data illustrated that LECT2 induces $H$. pylori killing in macrophages via activation of CD209a, Raf-1, NF- $\mathrm{BB}$, as well as through NO production. We believe that the identified signaling pathway is a novel and important mechanism for regulating macrophage activation. Further investigation is required to determine the effects and signaling mechanisms of LECT2 in other immune cells that also express CD209a.

\section{Conflicts of interest}

The authors declare no conflict of interest.

\section{ACKNOWLEDGMENTS}

Research supported by the Research Project of Chinese Ministry of Education (\#213017A), the Program for the Natural Science Foundation of China (\#81400606), the Natural Science Foundation of Ningbo City of China (\#2013A610166), and the KC Wong Magna Fund in Ningbo University.

\section{REFERENCES}

Abdullah Z and Knolle PA (2014). Scaling of immune responses against intracellular bacterial infection. EMBO J. 33: 2283-2294. http://dx.doi.org/10.15252/embj.201489055

Ahmed AU, Sarvestani ST, Gantier MP, Williams BR, et al. (2014). Integrin-linked kinase modulates lipopolysaccharideand Helicobacter pylori-induced nuclear factor $\mathrm{kB}$-activated tumor necrosis factor-a production via regulation of $\mathrm{p} 65$ serine 536 phosphorylation. J. Biol. Chem. 289: 27776-27793. http://dx.doi.org/10.1074/jbc.M114.574541

Ansari SA, Devi S, Tenguria S, Kumar A, et al. (2014). Helicobacter pylori protein HP0986 (TieA) interacts with mouse TNFR1 and triggers proinflammatory and proapoptotic signaling pathways in cultured macrophage cells (RAW 264.7). Cytokine 68: 110-117. http://dx.doi.org/10.1016/j.cyto.2014.03.006

Baccarini M (2005). Second nature: biological functions of the Raf-1 "kinase". FEBS Lett. 579: 3271-3277. http://dx.doi. org/10.1016/j.febslet.2005.03.024

Benson MD, James S, Scott K, Liepnieks JJ, et al. (2008). Leukocyte chemotactic factor 2: A novel renal amyloid protein. Kidney Int. 74: 218-222. http://dx.doi.org/10.1038/ki.2008.152

Blom N, Gammeltoft S and Brunak S (1999). Sequence and structure-based prediction of eukaryotic protein phosphorylation sites. J. Mol. Biol. 294: 1351-1362. http://dx.doi.org/10.1006/jmbi.1999.3310

Bussière FI, Chaturvedi R, Cheng Y, Gobert AP, et al. (2005). Spermine causes loss of innate immune response to Helicobacter pylori by inhibition of inducible nitric-oxide synthase translation. J. Biol. Chem. 280: 2409-2412. http:// dx.doi.org/10.1074/jbc.C400498200

Castaño-Rodríguez N, Kaakoush NO and Mitchell HM (2014). Pattern-recognition receptors and gastric cancer. Front.

Genetics and Molecular Research 15 (4): gmr15048889 
Immunol. 5: 336.

Chaturvedi R, Asim M, Lewis ND, Algood HM, et al. (2007). L-arginine availability regulates inducible nitric oxide synthase-dependent host defense against Helicobacter pylori. Infect. Immun. 75: 4305-4315. http://dx.doi. org/10.1128/IAI.00578-07

Chaturvedi R, de Sablet T, Coburn LA, Gobert AP, et al. (2012). Arginine and polyamines in Helicobacter pylori-induced immune dysregulation and gastric carcinogenesis. Amino Acids 42: 627-640. http://dx.doi.org/10.1007/s00726-011$\underline{1038-4}$

Chen TE, Xu XM, Liu P, Liang SY, et al. (2015). Elucidating the function and tolerance mechanism of gamma delta ( $\mathrm{g} \mathrm{d}$ ) $\mathrm{T}$ cells in a Helicobacter pylori infection model. Genet. Mol. Res. 14: 10543-10552. http://dx.doi.org/10.4238/2015. September.8.16

Cid TP, Fernández MC, Benito Martínez S and Jones NL (2013). Pathogenesis of Helicobacter pylori infection. Helicobacter 18 (Suppl 1): 12-17. http://dx.doi.org/10.1111/hel.12076

Dang MH, Kato H, Ueshiba H, Omori-Miyake M, et al. (2010). Possible role of LECT2 as an intrinsic regulatory factor in SEA-induced toxicity in d-galactosamine-sensitized mice. Clin. Immunol. 137: 311-321. http://dx.doi.org/10.1016/j. clim.2010.08.002

Dhillon AS, von Kriegsheim A, Grindlay J and Kolch W (2007). Phosphatase and feedback regulation of Raf-1 signaling. Cell Cycle 6: 3-7. http://dx.doi.org/10.4161/cc.6.1.3593

Forbus J, Spratt H, Wiktorowicz J, Wu Z, et al. (2006). Functional analysis of the nuclear proteome of human A549 alveolar epithelial cells by HPLC-high resolution 2-D gel electrophoresis. Proteomics 6: 2656-2672. http://dx.doi. org/10.1002/pmic.200500652

Granger DL, Taintor RR, Boockvar KS and Hibbs JB, Jr. (1996). Measurement of nitrate and nitrite in biological samples using nitrate reductase and Griess reaction. Methods Enzymol. 268: 142-151. http://dx.doi.org/10.1016/S00766879(96)68016-1

Gringhuis SI, den Dunnen J, Litjens M, van Het Hof B, et al. (2007). C-type lectin DC-SIGN modulates Toll-like receptor signaling via Raf-1 kinase-dependent acetylation of transcription factor NF-kappaB. Immunity 26: 605-616. http:// dx.doi.org/10.1016/j.immuni.2007.03.012

Gringhuis SI, den Dunnen J, Litjens M, van der Vlist M, et al. (2009). Dectin-1 directs T helper cell differentiation by controlling noncanonical NF-kappaB activation through Raf-1 and Syk. Nat. Immunol. 10: 203-213. http://dx.doi. org/10.1038/ni.1692

Hardbower DM, Asim M, Murray-Stewart T, Casero RA, Jr., et al. (2016). Arginase 2 deletion leads to enhanced M1 lmacrophage activation and upregulated polyamine metabolism in response to Helicobacter pylori infection. Amino Acids http://dx.doi.org/10.1007/s00726-016-2231-2.

Hayden MS and Ghosh S (2011). NF-kB in immunobiology. Cell Res. 21: 223-244. http://dx.doi.org/10.1038/cr.2011.13

Hong JB, Zuo W, Wang AJ and Lu NH (2016). Helicobacter pylori infection synergistic with IL-1b gene polymorphisms potentially contributes to the carcinogenesis of gastric cancer. Int. J. Med. Sci. 13:298-303. http://dx.doi.org/10.7150/ ijms.14239

Huang J, DeGraves FJ, Lenz SD, Gao D, et al. (2002). The quantity of nitric oxide released by macrophages regulates Chlamydia-induced disease. Proc. Natl. Acad. Sci. USA 99: 3914-3919. http://dx.doi.org/10.1073/pnas.062578399

Hu Y, Liu JP, Zhu Y and Lu NH (2016). The importance of Toll-like receptors in NF-kB signaling pathway activation by Helicobacter pylori infection and the regulators of this response. Helicobacter, in press http://dx.doi.org/10.1111/hel.12292

Hughes CE, Sinha U, Pandey A, Eble JA, et al. (2013). Critical Role for an acidic amino acid region in platelet signaling by the HemITAM (hemi-immunoreceptor tyrosine-based activation motif) containing receptor CLEC-2 (C-type lectin receptor-2). J. Biol. Chem. 288: 5127-5135. http://dx.doi.org/10.1074/jbc.M112.411462

Jones E, Adcock IM, Ahmed BY and Punchard NA (2007). Modulation of LPS stimulated NF-kappaB mediated Nitric Oxide production by PKCepsilon and JAK2 in RAW macrophages. J. Inflamm. (Lond.) 4: 23. http://dx.doi. org/10.1186/1476-9255-4-23

Kameoka Y, Yamagoe S, Hatano Y, Kasama T, et al. (2000). Val58Ile polymorphism of the neutrophil chemoattractant LECT2 and rheumatoid arthritis in the Japanese population. Arthritis Rheum. 43: 1419-1420. http://dx.doi. org/10.1002/1529-0131(200006)43:6<1419::AID-ANR28>3.0.CO;2-I

Kim G, Kim TH, Kang MJ, Choi JA, et al. (2016). Inhibitory effect of withaferin A on Helicobacter pylori-induced IL-8 production and NF-kB activation in gastric epithelial cells. Mol. Med. Rep. 13: 967-972.

Kumar N, Mariappan V, Baddam R, Lankapalli AK, et al. (2015). Comparative genomic analysis of Helicobacter pylori from Malaysia identifies three distinct lineages suggestive of differential evolution. Nucleic Acids Res. 43: 324-335. http://dx.doi.org/10.1093/nar/gku1271

Lu DY, Tang CH, Chang CH, Maa MC, et al. (2012). Helicobacter pylori attenuates lipopolysaccharide-induced nitric

Genetics and Molecular Research 15 (4): gmr15048889 
oxide production by murine macrophages. Innate Immun. 18: 406-417. http://dx.doi.org/10.1177/1753425911413164

Lu XJ, Chen J, Yu CH, Shi YH, et al. (2013). LECT2 protects mice against bacterial sepsis by activating macrophages via the CD209a receptor. J. Exp. Med. 210: 5-13. http://dx.doi.org/10.1084/jem.20121466

Oeckinghaus A, Hayden MS and Ghosh S (2011). Crosstalk in NF-kB signaling pathways. Nat. Immunol. 12: 695-708. http://dx.doi.org/10.1038/ni.2065

Osorio F and Reis e Sousa C (2011). Myeloid C-type lectin receptors in pathogen recognition and host defense. Immunity 34: 651-664. http://dx.doi.org/10.1016/j.immuni.2011.05.001

Park CG, Takahara K, Umemoto E, Yashima Y, et al. (2001). Five mouse homologues of the human dendritic cell C-type lectin, DC-SIGN. Int. Immunol. 13: 1283-1290. http://dx.doi.org/10.1093/intimm/13.10.1283

Polk DB and Peek RM, Jr. (2010). Helicobacter pylori: gastric cancer and beyond. Nat. Rev. Cancer 10: 403-414. http:// dx.doi.org/10.1038/nrc2857

Saito T, Okumura A, Watanabe H, Asano M, et al. (2004). Increase in hepatic NKT cells in leukocyte cell-derived chemotaxin 2-deficient mice contributes to severe concanavalin A-induced hepatitis. J. Immunol. 173: 579-585. http://dx.doi.org/10.4049/jimmunol.173.1.579

Sancho D and Reis e Sousa C (2012). Signaling by myeloid C-type lectin receptors in immunity and homeostasis. Annu. Rev. Immunol. 30: 491-529. http://dx.doi.org/10.1146/annurev-immunol-031210-101352

Suzuki-Inoue K, Fuller GL, García A, Eble JA, et al. (2006). A novel Syk-dependent mechanism of platelet activation by the C-type lectin receptor CLEC-2. Blood 107: 542-549. http://dx.doi.org/10.1182/blood-2005-05-1994

Uchida T, Nagai H, Gotoh K, Kanagawa H, et al. (1999). Expression pattern of a newly recognized protein, LECT2, in hepatocellular carcinoma and its premalignant lesion. Pathol. Int. 49: 147-151. http://dx.doi.org/10.1046/j.1440$\underline{1827.1999 .00836 . x}$

Yamagoe S, Mizuno S and Suzuki K (1998). Molecular cloning of human and bovine LECT2 having a neutrophil chemotactic activity and its specific expression in the liver. Biochim. Biophys. Acta 1396: 105-113. http://dx.doi. org/10.1016/S0167-4781(97)00181-4

Yamauchi K, Choi IJ, Lu H, Ogiwara H, et al. (2008). Regulation of IL-18 in Helicobacter pylori infection. J. Immunol. 180: 1207-1216. http://dx.doi.org/10.4049/jimmunol.180.2.1207

Genetics and Molecular Research 15 (4): gmr15048889 